\title{
Effect of background and foreground music on satisfaction, behavior, and emotional responses in public spaces of shopping malls
}

\author{
Fashu Yia , Jian Kang ${ }^{\mathrm{a}, \mathrm{b}, *}$ \\ ${ }^{a}$ Heilongjiang Cold Region Architectural Science Key Laboratory, School of \\ Architecture, Harbin Institute of Technology, Harbin 150001, China \\ ${ }^{b}$ UCL Institute for Environmental Design and Engineering, The Bartlett, \\ University College London (UCL), London WC1H ONN, United Kingdom \\ * Corresponding author
}

\begin{abstract}
The study aims at exploring the specific effects of different types of broadcast music in the public spaces of shopping malls on customers' satisfaction, behavior intention, and emotional responses to the commercial service environment. An experiment was carried out in a laboratory: photos taken and sounds recorded on-site were shown to participants, who were then asked to answer questionnaires based on approach-avoidance behavior and pleasure-arousal-dominance emotion theories. The results showed that background music can increase individuals' positive evaluation of the environment, facilitate approach behavior, and enhance pleasure and dominance emotions, while foreground music can increase arousal distinctly. The effect of music in a large atrium space is significantly greater when compared to other spaces. Men have a higher level of satisfaction and arousal than do women with specific music settings, while older people are less sensitive to music than their younger counterparts and more tolerant of the environment.
\end{abstract}

Keywords: Shopping malls, Background music, Foreground music, Satisfaction, Behavior, Emotion

Applied Acoustics

Date Received: 9 August 2018 Date Accepted: 24 October 2018 


\section{Introduction}

It is common for people to exhibit different affective and behavior responses according to stimuli from the physical environment. Extensive research has been conducted, and several theory models have been created to help explain these responses. Osgood et al. [47] proposed evaluation, activity, and potency as three factors of affective responses. In 1960, Rosenberg and other researchers [52] developed the ABC psychological model, proposing that affect, behavior, and cognition are the three types of responses that occur while interacting with stimuli. In 1974, Mehrabian and Russel introduced pleasure, arousal, and dominance as three independent emotional dimensions to describe people's state of feeling. In the field of environmental psychology, the pleasure-arousaldominance theory focuses on three basic dimensions of emotional responses and has been expanded and improved to become one of the most important methods of emotion research currently $[6,40]$.

Approach-avoidance behavior is a basic instinct of all organisms, including humans, and often appears in motivation, cognition, psychology, and behavior studies. In environmental psychology research, approach-avoidance behavior intention can be measured by the self-description of feelings and behavior [8,7,16]. Lewin et al. [38] presented a formula indicating the interaction relationship between an individual and the environment: $B=f(P, E)$ (in which $B=$ behavior; $P=$ persons; $E=$ environment). It can be seen from the formula that both the physical environment and social characteristics of people should be considered in human behavior studies. Furthermore, studies have found that people's cultural background, age, and local areas can affect their recreational behavior to a degree $[20,37,49]$. In the specific context of shopping malls, approach behaviors are seen as positive responses to an environment, such as a desire to stay in a particular facility and explore it, while avoidance behaviors include not wanting to stay or spend time exploring a place [59].

Store "atmospherics" defined as the effort to design buying environments to produce specific emotional effects, were first conducted by Kotler in 1973. Store atmospheric design is very important to managers and can even be the reason for a business's success or failure [10]. Therefore, researchers are increasingly working in this field using different classified environmental elements as dependent variables (such as crowding, colors, music and olfactory cues) and emotions, consumer/staff behavior as independent variables. Among these, elements concerning sound are considered an important component of store atmospherics $[9,32,59]$. Many previous studies have found that the sound environment of public indoor spaces (including shopping malls, supermarkets, banks, and hospitals) have notable effects on human's perception, evaluation, emotion and behavior in both indoor and outdoor spaces.

There are several acoustical qualities to describe sound environment such as loudness, frequency and sound pressure level. However, in an actual scene, soundscape which is defined as "acoustic environment as perceived or experienced and/or understood by a person or people, in context" [25], is a more appropriate quantity to describe the overall sound situation $[27,28,64,65]$. Previous research investigated the classification of sound source and evaluating dimensions of soundscape. Generally, sound sources can be classified into human activity sound, natural sound, and technical sound, etc. [12], and 
can be described by the dimensions of calmness, vibrancy, pleasantness and eventfulness [2]. Retail environment of shopping malls is a typical built indoor environment, soundscape of which includes broadcasting music, footsteps, surrounding speech, air-conditioning [14,42]. Among them, the influence of broadcasting music, as one of the designable factors of retail environment, on individual responses in the shopping environment is paid more attention by designers and managers.

Many researchers studied on the effect of music in retail spaces [21,55]. Studies have examined the impacts of music, such as its tempo, volume, style, complexity, familiarity, and background or foreground type [24,29,54,63], focusing on business benefits and revealing the impact of sound on people's responses [26] leading to store turnover and income $[4,15]$. Some studies have explored the aspects of evaluation, attitude, and cognition with respect to their influence on human attention and information acquisition $[17,69,22,44,46]$. Meanwhile, findings on the multiple dimensions of the time effect, such as cognition of duration, actual time spent, waiting time, and task accomplished time $[1,3,13,23,30,63]$, have expanded the literature. For evaluation and attitude, the "fit" of music helps build and enhance people's perception [31] and attitude of a store or its components, affects customers' feeling intensity of satisfaction and pleasure, and influences the evaluation of the store as a whole [17]; Gorn et al., 1993; [22]. As regards affection and emotion, background music can lead to specific emotions, beliefs, and physiological changes [11]. In other kind of indoor environments, self-selected music can reduce the physiological parameters representing stress and anxiety [36]. Patients will feel less stressed and will relax with music in the waiting area of hospitals [58]. In terms of behavior, music helps individuals establish a connection with store staff and other customers, enhances people's desire to participate $[4,18,39,56]$, as well as increases or reduces individuals' possibility of exploring and browsing according to need $[1,57]$. Indeed, enjoyable music can increase the potential of impulse purchase [39], whereas music tempo can influence the pace of customers, with fast-tempo music raising shopping speed [33] and sales volume to a certain degree $[43,45]$.

Most of the previous studies have aimed at helping improve store profitability. Their purpose for measuring emotion and behavior has been to improve indices that are beneficial to entrepreneurs, such as staying time, chance of impulse purchase, and turnover frequency, regardless of consumers' psychological and emotional needs [19]. Moreover, most focused on retail space or spaces where goods are sold. Shopping malls' public spaces like atriums and corridors, which are not principally for selling goods but are where customers can walk through, relax, and rest, have not been discussed. In addition, many previous researchers have focused on music types, whereas background and foreground music have not received much academic attention [61], especially the interaction effect of the audio-visual environment with space types. Existing research has mostly considered retail spaces and customers in Western countries; research aiming at the special shopping habits and family relationship model is limited $[34,37,41]$.

Therefore, the aim of this study is to investigate the individual responses affected by the building environment in specific space types, particularly the effect of background and foreground music on an individual's satisfaction, emotion, and behavior responses in the public spaces of shopping malls. The research questions are as follows. In the public spaces of shopping malls in China: a) What is the influence of background and foreground music on individual responses? b) In different types of space, what are the 
different influences of music on individual responses? c) How do customers' personal differences affect their responses to music? In order to answer these questions, testing the effect of specific environmental factors on people is needed, which is to control visual and audio variables accurately in specific types of space. A laboratory experiment was conducted in which images, sound types, and space types were accounted for in combinatorial designs. Participants were invited to answer a corresponding questionnaire based on approach-avoidance behavior and pleasure-arousal-dominance emotion theories after observing every scene.

\section{Methods and material}

\subsection{Field survey}

At the beginning of this study, a field survey involving seven shopping malls was conducted to obtain the audio-visual perception features as the basis for selecting materials in the laboratory experiment and space classification as the basis for analyzing music on individual responses in different spaces. The site environment was recorded using a digital camera and a 10-access sound signal collection system. One hundred and fifty questionnaires were distributed to investigate people's perception of audiovisual elements. People were asked to select the audio and visual elements they noticed and their evaluation of the environment. A space type cluster analysis was also carried out to classify the public spaces based on the accessible area $\left(\mathrm{m}^{2}\right)$, passage width $(\mathrm{m})$, space height $(\mathrm{m})$, number of interface, and interface height $(\mathrm{m})$ of the existing shopping malls.

Survey results are as follows: (1) For auditory elements, the sound of voices and footsteps were identified in all scenes after careful listening by five researchers. There was easily identifiable background or foreground music playing in some of these scenes. The on-site participants selected the same audio elements. (2) For visual elements, the three highest frequency elements of onsite photos were store interface, large advertising, and guide signs. The top three elements selected by the participants were store interface, large advertising, and crowd, indicating that these four visual elements are the typical signs of a shopping environment. (3) By comparing the site photos and the results of questionnaires, each visual element is limited to a pixel proportion range. For instance, the image pixel proportion of people was about 3.5\%, making shoppers feel the environment was neither crowded nor desolate. See details in Section 2.4.2. (4) The spaces were widely classified as "large space" (the ground level of a large atrium), "appropriate space" (the ground level of a narrow atrium or a wide aisle) and "narrow space" (a narrow aisle).

\subsection{Laboratory settings}

The experiment was conducted in the audiometric laboratory of a university in Harbin, China; the lab has a volume of $186 \mathrm{~m}^{3}$ and background noise of $11 \mathrm{~dB}(\mathrm{~A})$. Fig. 1 shows the layout schematic diagram of the laboratory. A 75-inch LCD television set (model number UA75F6400) displayed the images taken on-site in the participants' visual field when seated in the designated seat. Audio was provided by an RME FireFace UFX sound card and a Genelec sound system, which can create a surround-sound effect deemed realistic for the sound recordings. Only the necessary equipment and no other objects were in the laboratory so that subjects were not distracted [48]. 


\subsection{Subjects}

Some of the participants were recruited from among postgraduates and staff members of a university in China. The others were recruited from among staff of a public institution in China. They were informed by a volunteer recruitment notice published in their communication groups through a social software. Informed consent was obtained from all participants, and they all self-reported normal or corrected-to-normal hearing and vision. All the participants who completed the experiment were given a small gift and some snack as a token of appreciation. Participants' characteristics are shown in Table 1.

\subsection{Experiment materials}

During the experiment, in order to cover the range of activity present at the public space at different times during the day, 11 scenes were shown. However, data of only 10 scenes were processed and analyzed. On weekends and holidays, many malls hold special events like sales, talent shows, games, and so on. The 11th scene constituted a talent show held in the large atrium, which included intermittent music, the host's voice, and the background noise of the audience's voices and footsteps. Its audio-visual setting was not comparable to the other 10 scenes and therefore was excluded from the study.

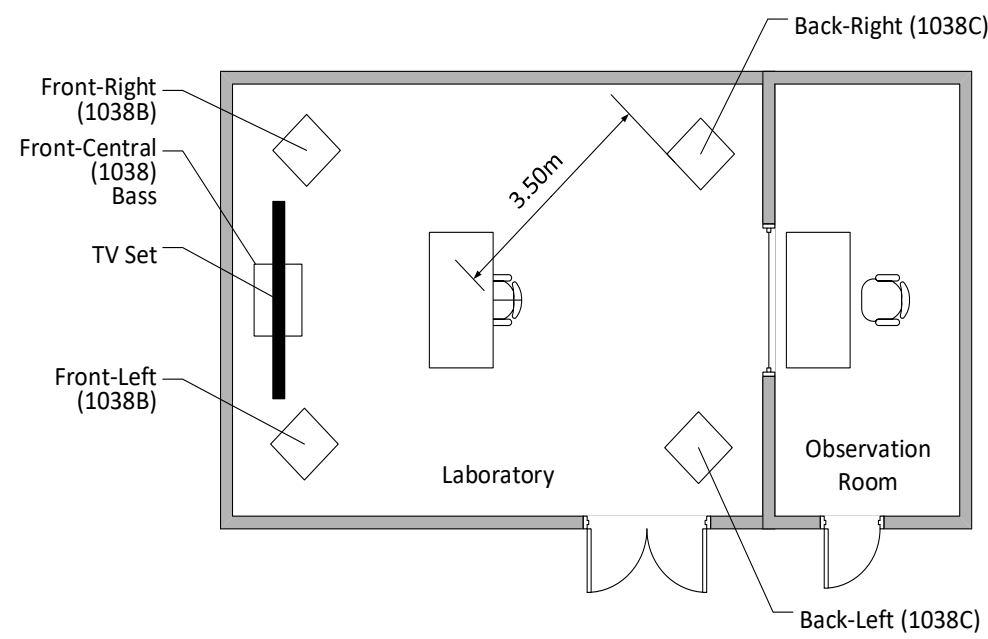

Table 1

Fig. 1. Laboratory Layout Schematic.

Experimental Subjects' Characteristics.

\begin{tabular}{|c|c|c|c|c|c|c|c|}
\hline Gender & & Age & & Educational Background & & Occupatio & \\
\hline Male & 40 & $18-27$ & 23 & High School/Junior College & 9 & Students & 27 \\
\hline Female & 30 & $28-44$ & 30 & Undergraduate & 26 & Teachers & 2 \\
\hline & & $45-60$ & 17 & Graduate & 21 & Staff & 19 \\
\hline & & & & PhD & 14 & Managers & 6 \\
\hline & & & & & & Others & 16 \\
\hline
\end{tabular}

Total 70

\subsubsection{Sound settings}

Three kinds of music settings were designed: no music (NM), background music (BGM), and foreground music (FGM). BGM refers to instrumental music without recognizable language and lyrics, while FGM includes musical instruments and singers, is recorded in recording studios, and has recognizable language or lyrics $[61,62]$. All three settings included sound elements of footsteps and a speaking voice to recreate the actual sound 
environment. BGM settings included a piece of piano music with tempos within 105-120 bpm. For FGM settings, the music excerpts were "inclusive", "non-aversive", and had good sound quality in a highly reverberant environment [35]. In this study, two familiar pop songs were selected for the acoustic environment of the shopping mall's public space. One of the songs is "May you be happy and prosperous" by Andy Lau with Chinese lyrics and tempo of $126 \mathrm{bpm}$. The other one is "My love" by Westlife with English lyrics and tempo of $130 \mathrm{bpm}$. Both of the songs were released at the beginning of the 21st century and can be heard often in public spaces, so that there is no familiarity difference among participants. Before the experiment, the A-weighted equivalent continuous sound level (LAeq) of each sound signal collected in the field was listened to and recorded by a dummy head. The LAeq of the playback sound was kept within the range of $65 \pm 3 \mathrm{~dB}(\mathrm{~A})[66]$ and played for $30 \mathrm{~s}[50,51,60]$ in the experiment.

\subsubsection{Image settings}

All images were photographed on site. One store from the Wanda Commercial chain, one from the CapitaLand chain, and one from the local brand Hongbo Commercial were chosen to ensure that the experiment displayed both national and local decoration styles. These stores contained a certain amount of narrow and wide public spaces. The scenes in the images were adjusted on the basis of the following principles. A) The visual scenes conform to the vision range of the human eyes (left and right 60 degrees each, up 60 degrees, and down 70 degrees). B) On the basis of the normal level of sight height of adults (1.6-1.7 $\mathrm{m}$ high), the images are as large as possible without perspective distortion. C) The depth of field shows the actual situation of the public spaces in shopping malls, and representational objects occupying a large area of visual scene must be avoided. D) The pixel proportion of each visual element is determined as follows: business interface, $15 \%-25 \%$; large-scale advertisement, $2 \%-5 \%$; and people, $3 \%-5 \%$. Moreover, the elements of business interface and advertisement should meet the requirement separately or occupy $17 \%-25 \%$ combined to ensure the visual scene is representative of the public spaces of shopping malls. Fig. 2 is an example of the adjustment. In addition, text prompts appeared on the screen before and after the experiment. Gray $(R=75, G=75, B=75)$ was selected as the background color of the experimental program and white as the color of the text to avoid the visual effects of temporary retention. A total of 10 images were selected, constituting 10 audio-visual scenes with the sound settings described in the above section.

\subsubsection{Audiovisual scenes}

According to the field investigation of shopping malls, their public spaces can be divided into three types according to aisle width, height, and spatial interface. Table 2 shows the scene environment settings and space types. Excel (=RAND) was used to generate all the scenes in 10 random orders, with seven participants in each group. 


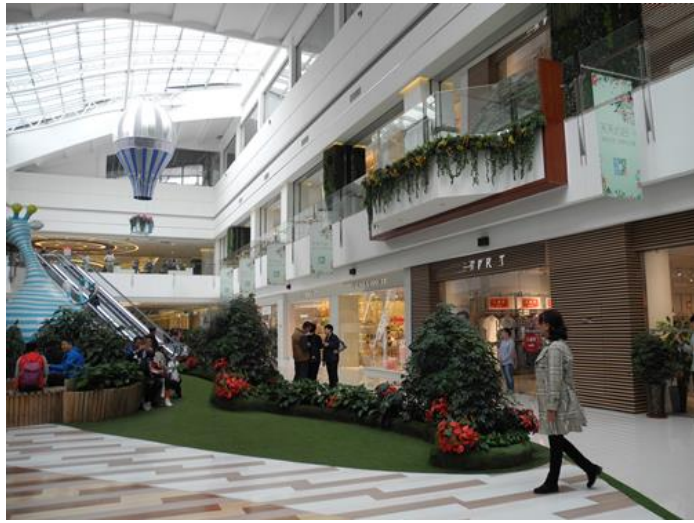

a) One of the ten visual image used for the

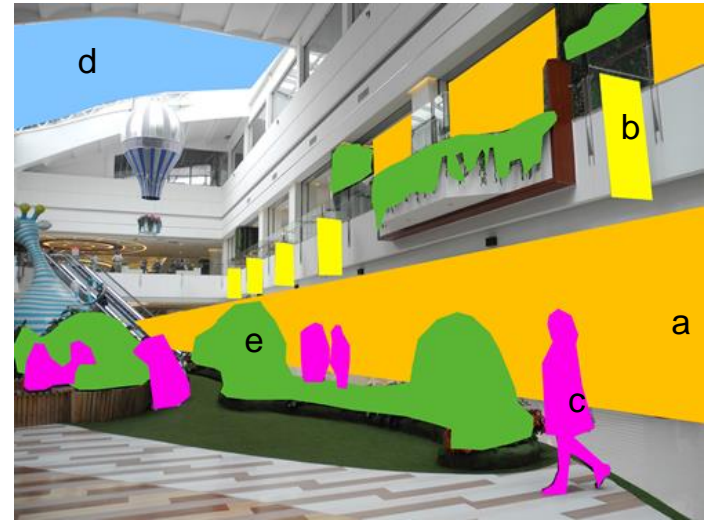

b) Pixel proportion of each visual element experiment

Fig. 2. The Pixel Proportion Control of Images for the Experiment. The Pixel proportion of each visual element in b): a. Business interface: $14.64 \%$; b. Advertisement: $2.41 \%$; c. People: $5.17 \%$; d. Daylight interface: $5.52 \%$; e. Plants: $8.57 \%$.

Table 2

Audio Settings and Space Types of Experiment Scenes

\begin{tabular}{|c|c|c|}
\hline No. & Space Types & Space Feature \\
\hline \multicolumn{3}{|l|}{ No music } \\
\hline 1 & Appropriate & Ground-level of narrow atrium \\
\hline $\begin{array}{l}2 \\
3\end{array}$ & Wide & Ground-level of open, large atrium \\
\hline 4 & Narrow & $\begin{array}{l}\text { Aisle, two-sided interface for counters, same story height as each } \\
\text { floor }\end{array}$ \\
\hline \multicolumn{3}{|c|}{ Background music } \\
\hline 5 & Appropriate & $\begin{array}{l}\text { Aisle, two-sided interface, one side store and one side counter, same } \\
\text { story height as each floor }\end{array}$ \\
\hline $\begin{array}{l}6 \\
7\end{array}$ & Wide & Ground-level of open, large atrium \\
\hline 8 & Narrow & $\begin{array}{l}\text { Aisle, two-sided interface for counters, same story height as each } \\
\text { floor }\end{array}$ \\
\hline \multicolumn{3}{|c|}{ Foreground music } \\
\hline 9 & Appropriate & Ground-level of narrow atrium \\
\hline 10 & Wide & Ground-level of open, large atrium \\
\hline
\end{tabular}

\subsection{Experiment questionnaire}

The experimental questionnaire based on Mehrabian and Russell's [40] pleasurearousal-dominance emotion theory and approach-avoidance behavior theory comprised three parts. The first part considered shopping habits, which was expected to help the participants visualize the shopping environment and become familiar with the laboratory atmosphere. The second part considered the participants' perception of the corresponding scenes, including the description of the behavior intention and adjectives related to emotions, using a seven-point Likert scale and a seven-point semantic difference scale. This section, which contained 11 questions, is the core part of this study. The third part considered the subjects' personal characteristics, including age, gender, educational background, and job. The questionnaire used five A4-sized pages.

Simple forward/reverse descriptive statements were used to survey the participants' evaluation and behavior intention for the second part of the questionnaire. The subsequent dependent variables analysis involved satisfaction, approach-avoidance behavior, exploring behavior, communication with others, pleasure, arousal, and dominance, of which the score source is shown in Table 3. Words were in Chinese in 
the experiment.

Table 3

Source of Scores for Dependent Variables

\begin{tabular}{ll}
\hline Dependent Variables & Source of Scores \\
\hline Satisfaction & $\begin{array}{l}\text { I am very satisfied with the environment of the store. } \\
\text { I like this environment. }\end{array}$ \\
Approach-avoidance Behavior & I might not come to this store any more. \\
& $\begin{array}{l}\text { I might stay here longer than planned. } \\
\text { I would like to take some time to browse the store. } \\
\text { I would like to shop at this store. }\end{array}$ \\
I want to get out of this store as soon as possible. \\
Communication with Others & $\begin{array}{l}\text { I will chat with other customers I meet here. } \\
\text { I will try to hide from others and not talk to strangers. }\end{array}$ \\
Emotion & $\begin{array}{l}\text { Satisfied-Depressed, Happy-Unhappy, Comfortable-Restless, } \\
\text { Gleasure }\end{array}$ \\
Grousal & Fevered-Peaceful, Excited-Unexcited, Stimulated-Relaxed, \\
Awakened-Drowsy & Active-Passive, Uncontrolled-Controlled \\
Dominance &
\end{tabular}

\subsection{Experiment procedure}

Before the experiment, each participant had a scheduled time set in advance, and the main part of the experiment was controlled to last approximately $20 \mathrm{~min}$ to avoid errors due to fatigue. The experiment procedure is shown in Fig. 3. First, a participant enters the lab, is guided to a seat, and then is given five minutes to adapt to the laboratory environment. Second, the participant is introduced to the experiment procedure and operating essentials. Third, the experiment begins.

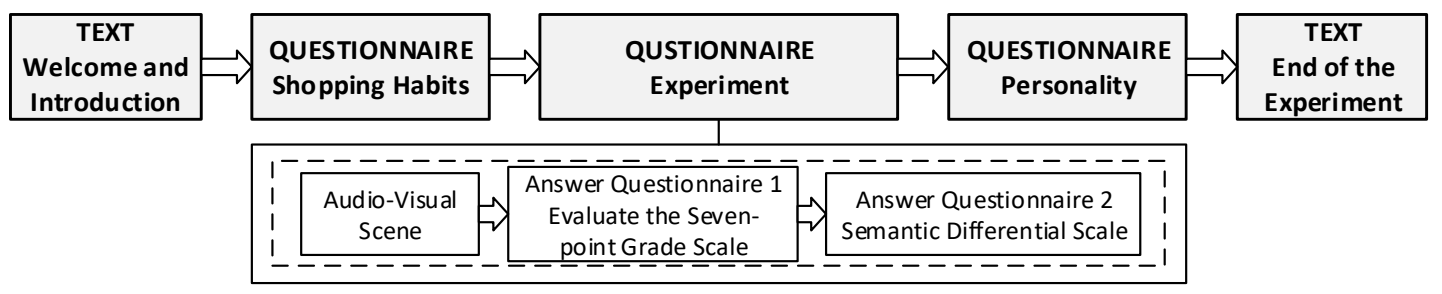

\section{Results}

Fig. 3. Experimental Flow Diagram.

\subsection{Music settings and individual responses}

The statistical analysis of this study needs to test the significance of difference between means of two or more categories of variables. T-test (two-tailed) was used when two categories of variables are compared, while one-way ANOVA is used when three or more categories of variables are compared, and multiple comparison (post hoc test) was further used to test which pairs of variables have significant differences. The data satisfies assumption of normality (KS significance of each variable was tested, sig <.005), homogeneity of variance (Levene's test of homogeneity was used to judge) and additivity. The significance level was set at 0.05 .

The data were submitted to a mixed design analysis of variance (ANOVA) of all the individual responses $\times$ music settings (NM, BGM, and FGM), as shown in Table 4.

Multiple comparisons indicated that the satisfaction increased between NM and BGM ( $p$ $<.001)$, also between NM and FGM $(p=.002)$. Approach-avoidance behavior increased 
between NM and BGM $(p<.001)$, also between BGM and FGM $(p=.049)$. Pleasure increased between NM and BGM $(p<.001)$, also between BGM and FGM $(p=.001)$. Arousal increased between NM and FGM $(p<.001)$, also between BGM and FGM ( $p$ $<.001)$. Dominance increased between NM and BGM $(p<.001)$, also between NM and $\operatorname{FGM}(p=.014)$.

Table 4

ANOVA Result of Individual Responses $\times$ Music Settings

\begin{tabular}{clll}
\hline Individual Responses & $F(2,697)$ & $p$ & $\eta_{\mathrm{p}}^{2}$ \\
\hline Satisfaction & 18.957 & $<.001$ & .052 \\
Approach-avoidance Behavior & 11.354 & & .032 \\
Pleasure & 11.928 & & .033 \\
Arousal & 19.443 & & .053 \\
Dominance & 13.748 & & .038 \\
\hline Note. $p<.05$ are in boldface. & &
\end{tabular}

\subsection{Space types and individual responses}

Does people have different perception of the same environmental stimuli in different kinds of space and make different responses? In this study, three spatial types, namely large, appropriate and narrow spaces, were selected in the experimental scenes to test whether there was statistically significant differences. Table 5 shows the ANOVA result of individual responses $\times$ space types with NM and BGM.

\section{Table 5}

ANOVA Results of Individual Responses $\times$ Space Types

\begin{tabular}{cllllll}
\hline & NM & \multicolumn{5}{l}{ BGM } \\
\cline { 2 - 7 } Individual Responses & $F(2,277)$ & $p$ & $\eta p^{2}$ & $F(2,277)$ & $p$ & $\eta p^{2}$ \\
\hline Satisfaction & 3.749 & $\mathbf{0 . 0 2 5}$ & .026 & 27.745 & $<.001$ & .167 \\
Approach-avoidance & 2.455 & 0.088 & .017 & 26.454 & $<.001$ & .160 \\
Behavior & 0.200 & 0.819 & .001 & 21.576 & $<.001$ & .135 \\
Pleasure & 0.433 & 0.649 & .003 & 1.707 & 0.183 & .012 \\
Arousal & 1.472 & 0.231 & .011 & 9.817 & $<.001$ & .066 \\
Dominance &
\end{tabular}

Note. $p<.05$ are in boldface.

With NM, multiple comparisons indicated that the satisfaction increased between wide and appropriate space $(p=.011)$, also between appropriate and narrow space $(p=.024)$. With BGM, satisfaction increased between wide and appropriate space $(p<.001)$, between appropriate and narrow space $(p=.012)$, and between wide space and narrow space $(p<.001)$. Approach-avoidance behavior increased between wide and appropriate space $(p<.001)$, between appropriate and narrow space $(p=.047)$, between wide and narrow space $(p<.001)$. Pleasure increased between wide and appropriate space $(p<.001)$, also between wide and narrow space $(p<.001)$. Dominance increased between wide and appropriate space $(p<.001)$, also between wide and narrow space $(p<.001)$. With FGM, the data were submitted to a mixed design analysis of variance $(t-$ test) of emotional responses $\times$ space types (wide and appropriate space). The results revealed significant interactions of arousal $\times$ space types interaction, Levene: $F=.601$, $p=.440>.05, \mathrm{t}(138)=2.113, p=.036$.

Large atrium space is more and more common in shopping malls, providing a multifunction space for selling, exhibition, and activities. Thus, whether there exist differences of music effect in large atrium space was examined separately. Table 6 shows the ANOVA results of individual responses $\times$ music settings in large atrium space. Multiple comparisons indicated that the satisfaction increased between NM and BGM $(p<.001)$, 
also between BGM and FGM $(p<.001)$. Approach-avoidance behavior increased between NM and BGM $(p<.001)$, also between BGM and FGM $(p<.001)$. Pleasure increased between NM and BGM $(p<.001)$, also between BGM and FGM $(p<.001)$. Arousal increased between NM and FGM $(p<.001)$, also between BGM and FGM ( $p$ $=.001)$. Dominance increased between NM and BGM $(p<.001)$, also between BGM and $\operatorname{FGM}(p<.001)$.

\section{Table 6}

ANOVA Results of Individual Responses $\times$ Music Settings in Large Atrium Space

\begin{tabular}{clll}
\hline Individual Responses & $F(2,277)$ & $p$ & $\eta p^{2}$ \\
\hline Satisfaction & 41.956 & $<.001$ & .232 \\
Approach-avoidance Behavior & 34.813 & & .201 \\
Pleasure & 24.239 & & .149 \\
Arousal & 11.437 & & .076 \\
Dominance & 23.319 & & .144 \\
\hline
\end{tabular}

Note. $p<.05$ are in boldface.

\subsection{Personal factors and individual responses}

In terms of gender, the data were submitted to a mixed design analysis of variance $(t-$ test) of individual responses $\times$ gender (male, female). The results of $t$-test revealed significant interactions of satisfaction $\times$ gender interaction, Levene: $F=1.907, p$ $=.168>.05, \mathrm{t}(278)=2.485, p=.014<.05$, and arousal $\times$ gender interaction, Levene: $\mathrm{F}=.408, \mathrm{p}=.524>.05, \mathrm{t}(138)=2.254, p=.026$.

As for age, ANOVA results of individual responses $\times$ music settings of different ages are shown in Table 7. For the young group of 18-27 years old, multiple comparisons indicated that the satisfaction increased between NM and BGM $(p<.001)$. Approachavoidance behavior increased between NM and BGM $(p=.001)$. Pleasure increased between NM and BGM $(p<.001)$, also between NM and FGM $(p<.001)$. Arousal increased between NM and FGM $(p<.001)$, between NM and BGM $(p=.003)$, also between BGM and FGM $(p<.001)$. Dominance increased between NM and BGM $(p$ $<.001)$, also between NM and FGM $(p=.002)$. For the mid-age group, multiple comparisons indicated that satisfaction increased between NM and BGM $(p<.001)$, also between NM and FGM ( $p=.007)$. Approach-avoidance behavior increased between NM and $\operatorname{BGM}(p=.003)$. Pleasure increased between NM and BGM $(p=.005)$. Arousal increased between NM and FGM $(p<.001)$, between BGM and FGM $(p<.001)$. Dominance increased between NM and BGM $(p=.008)$. For the oldest group, multiple comparisons indicated that satisfaction increased between NM and BGM $(p=.011)$.

Table 7

ANOVA Results of Individual Responses $\times$ Music Settings of Different Ages

\begin{tabular}{|c|c|c|c|c|c|c|c|c|c|}
\hline \multirow[b]{2}{*}{$\begin{array}{l}\text { Individual } \\
\text { Responses }\end{array}$} & \multicolumn{3}{|c|}{ Age $18-27$} & \multicolumn{3}{|c|}{ Age $28-44$} & \multicolumn{3}{|c|}{ Age $45-60$} \\
\hline & $\begin{array}{l}F \\
(2,237)\end{array}$ & $p$ & $\eta p^{2}$ & $\begin{array}{l}F \\
(2,287)\end{array}$ & $p$ & $\eta p^{2}$ & $\begin{array}{l}F \\
(2,167)\end{array}$ & $p$ & $\eta p^{2}$ \\
\hline $\begin{array}{l}\text { Satisfaction } \\
\text { Approach- }\end{array}$ & 9.331 & $<.001$ & .073 & 8. 244 & $<.001$ & 054 & 3.373 & .037 & .039 \\
\hline $\begin{array}{l}\text { avoidance } \\
\text { Behavior }\end{array}$ & 6. 731 & .001 & .054 & 4. 463 & .012 & 030 & 1. 807 & 0.167 & .021 \\
\hline Pleasure & 11.655 & $<.001$ & .090 & 4. 438 & .013 & 030 & 1. 078 & 0.343 & .013 \\
\hline Arousal & 29.003 & $<.001$ & .197 & 9. 290 & $<.001$ & 061 & 0.050 & 0.951 & .001 \\
\hline Dominance & 13. 673 & $<.001$ & .103 & 3. 713 & .026 & 025 & 1. 174 & 0.312 & .014 \\
\hline
\end{tabular}

Note. $p<.05$ are in boldface.

ANOVA analysis of individual responses $\times$ ages of different music settings were also 
examined, as shown in Table 8. With NM, multiple comparisons indicated that pleasure increased between young and mid-age group $(p=.016)$, also between young and old group $(p<.001)$. Arousal increased between mid-age and old group $(p<.001)$, between young and mid-age group $(p=.022)$. Dominance increased between young and old group $(p<.001)$, also between mid-age and old group $(p=.002)$. With BGM, multiple comparisons indicated that pleasure increased between young and old group ( $p=.004)$. Arousal increased between young and old group $(p=.001)$, between mid-age and old group $(p<.001)$. Dominance increased between mid-age and old group $(p=.008)$.

Table 8

ANOVA Results of Individual Responses $\times$ Ages

\begin{tabular}{cllllll}
\hline & NM & \multicolumn{7}{c}{ BGM } \\
\cline { 2 - 7 } Individual Responses & $F(2,277)$ & $p$ & $\eta p^{2}$ & $F(2,277)$ & $p$ & $\eta p^{2}$ \\
\hline Satisfaction & 2.694 & .069 & .019 & 1.911 & .150 & .014 \\
Approach-avoidance & 3.899 &. $\mathbf{0 2 1}$ & .027 & 2.046 & .131 & .015 \\
Behavior & 11.393 & $<.001$ & .076 & 6.413 & .002 & .044 \\
Pleasure & 7.916 & $<.001$ & .054 & 8.211 & $<.001$ & .056 \\
Arousal & 7.681 &. $\mathbf{0 0 1}$ & .053 & 3.632 &. $\mathbf{0 2 8}$ & .026 \\
Dominance & & & & & &
\end{tabular}

Note. $p<.05$ are in boldface.

\section{Discussion}

\subsection{Sound and individual responses}

Fig. 4(a) shows satisfaction and behavior intention with different music settings. It can be seen that satisfaction is the lowest in the absence of music. With BGM present, the participants' general satisfaction significantly increases by 0.75 (18.25\% compared with NM), and with FGM present, it increases by 0.46 (11.19\% compared with NM). Results show that music can help build and enhance customers' positive attitude to the environment of store public spaces and the entire store building, confirming previous results [17].

In terms of behavior intention, when BGM exists, the overall approach-avoidance behavior evaluation increases by $10.82 \%$ compared with NM and by $5.13 \%$ compared with FGM; exploratory behavior increases by $12.41 \%$ compared with NM. Thus, the existence of BGM can increase customers' approach behavior and may extend their stay time in the store, and thus may help improve commercial activity, store sales, and profits.

Fig. 4(b) shows emotional responses according to different music settings. When the setting is NM, the pleasure level is the lowest, at 0.58 , whereas with BGM, the pleasure level increases to 1.04, and with FGM, it increases to 0.99. Meanwhile, dominance shows the same trend as pleasure. The evaluation is 0.36 at the lowest with NM and rises to 1.03 with $B G M$ and 0.75 with $F G M$. This finding is explained as the tendency in which, owing to the main sound environment being characterized by footsteps and voices without music's masking effect, people's irritability and agitation are more easily provoked. Therefore, the surrounding environment plays a more important role in people's negative feelings, which reduces the degree of pleasure and dominance in the environment. Notably, the effect on arousal is quite different. With FGM, the arousal level is the highest at 0.15 , significantly different from NM and BGM. FGM containing recognizable lyrics attracts participants' attention and increases their arousal. BGM without lyrics becomes part of the ambient sound and helps ease people's mood and reduce arousal, which corresponds to previous results $[36,58]$. 


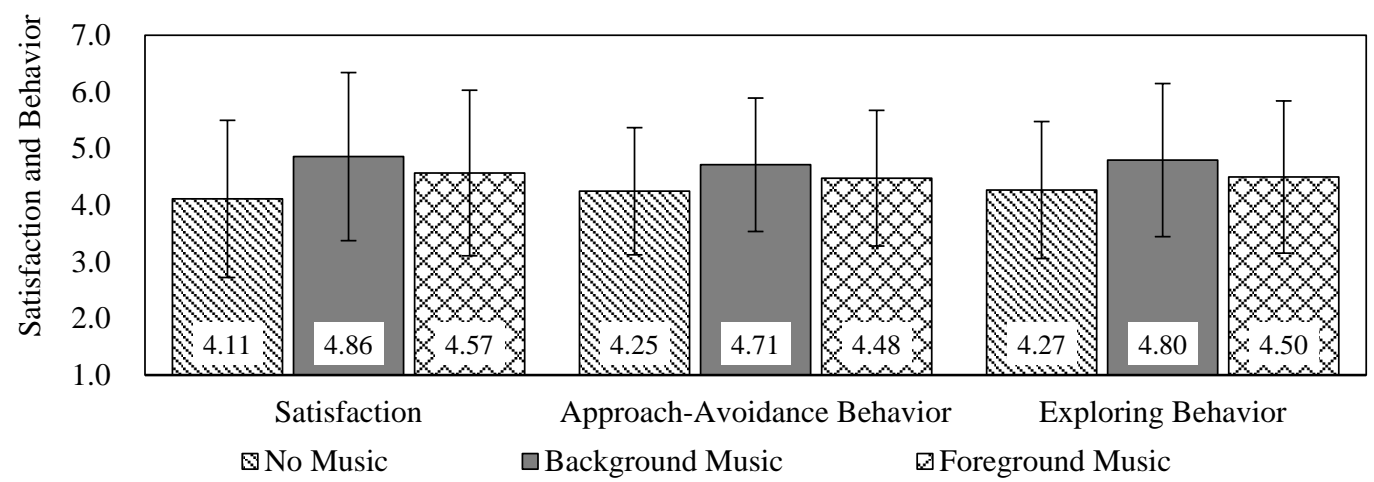

(a) Satisfaction and Behavior Intention

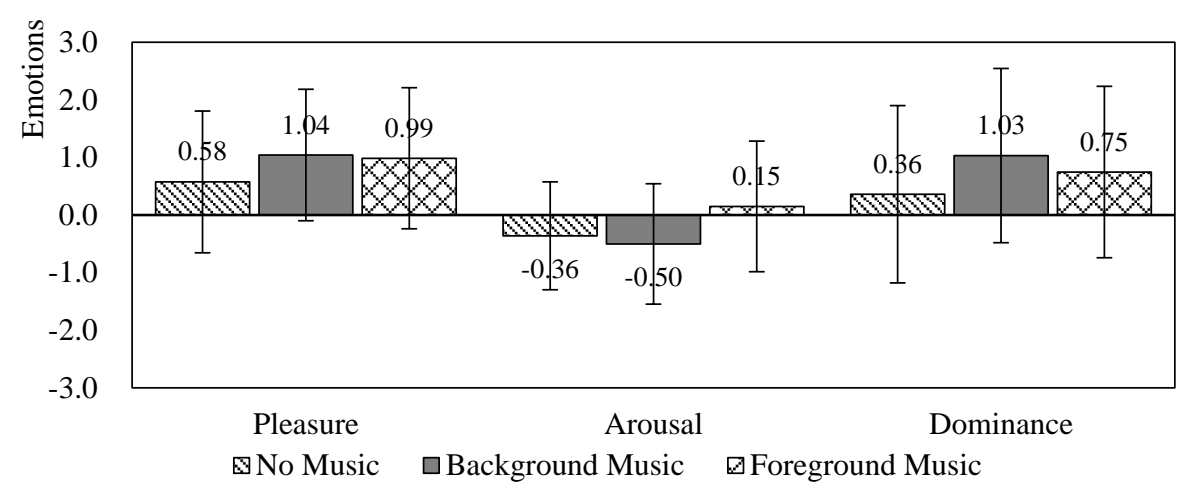

b) Emotional Responses

Fig. 4. Effects of Music on Individual Responses

For the overall emotional responses to the environment of shopping mall public spaces, the three points of PAD emotion responses value of each music setting are distributed in the following 3-D plane in Fig. 5. According to pleasure, arousal, and dominance threedimension emotion theory, with or without FGM and BGM, the participants' emotional responses are within the harmonious scope, indicating that the environment of public spaces does not cause extreme emotions (whether positive or negative). The positions of the three points relative to the original point indicate the trending emotions described by the adjectives in the corresponding direction. As shown in Fig. 5, with NM, the three dimensions of pleasure, arousal, and dominance tend to be zero: the most harmonious condition. With FGM, the evaluation tends to be pleasing, whereas the evaluation tends to be serene and restful with BGM. 


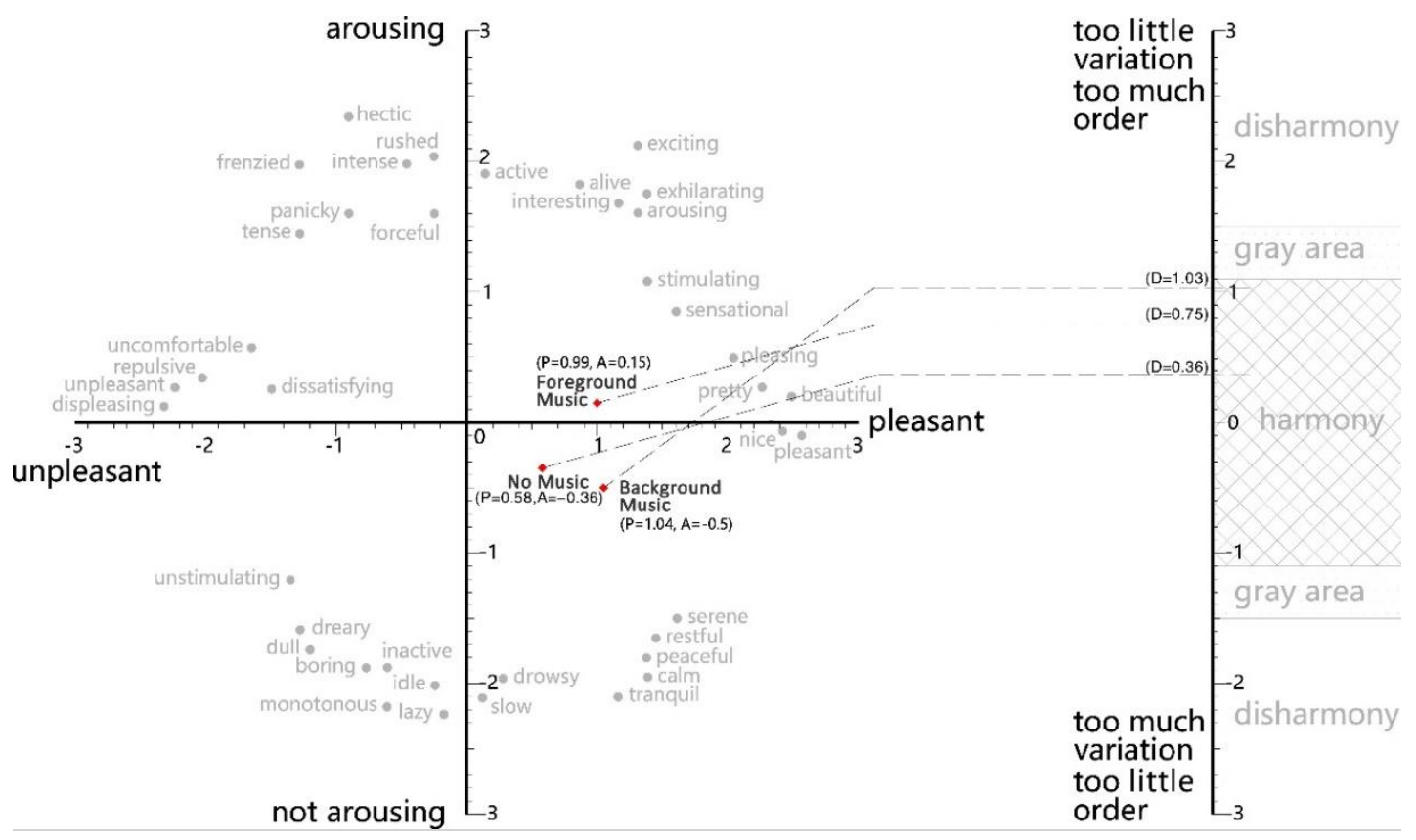

Fig. 5. Words Describing Emotions in the Three Music Settings [5,6,53].

To compare this study's results with those of previous studies, Yalch and Spangenberg [61] found that music has a statistically significant effect only on arousal. Arousal appears the lowest when there is BGM and the highest with NM, possibly because the lack of music makes people more active. In this study, the result that BGM is linked to people's lowest arousal level is congruent with previous studies. However, this study found that FGM causes the highest arousal degree. In addition, BGM is also found to have a significant effect on pleasure and dominance in comparison with NM. This may be explained, to some extent, by cultural differences: Chinese customers may be more sensitive and their emotions may be more obviously influenced compared with their Western counterparts.

\subsection{Space types and individual responses}

Fig. 6 shows the effect of space types on individual responses. Without music, as shown in Fig. 6(a), in the appropriate space, satisfaction increases by 0.51 and 0.53 compared with wide and narrow spaces, respectively. Exploring behavior also rises by 0.38 and 0.45 . The reason is that the wide space scale is large with indistinct boundaries, while the narrow space scale is small, leading people to feel crowded. By contrast, the appropriate space with moderate scale is more satisfying and encourages further exploration.

With BGM, as shown in Fig. 6(b) and (c), space types affect all the individual responses except arousal. Scores move from high to low in satisfaction, behavior intention, pleasure, and dominance for wide, appropriate, and narrow spaces; this result is positively correlated with space scale. The evaluations of wide space with BGM are significantly higher than those of other spaces.

With FGM, space types significantly affect subjects' arousal, as shown in Fig. 6(d). According to previous analysis, it is evident that FGM can improve arousal; arousal greatly increases by 0.40 with FGM in wide space compared with that in narrow spaces. 


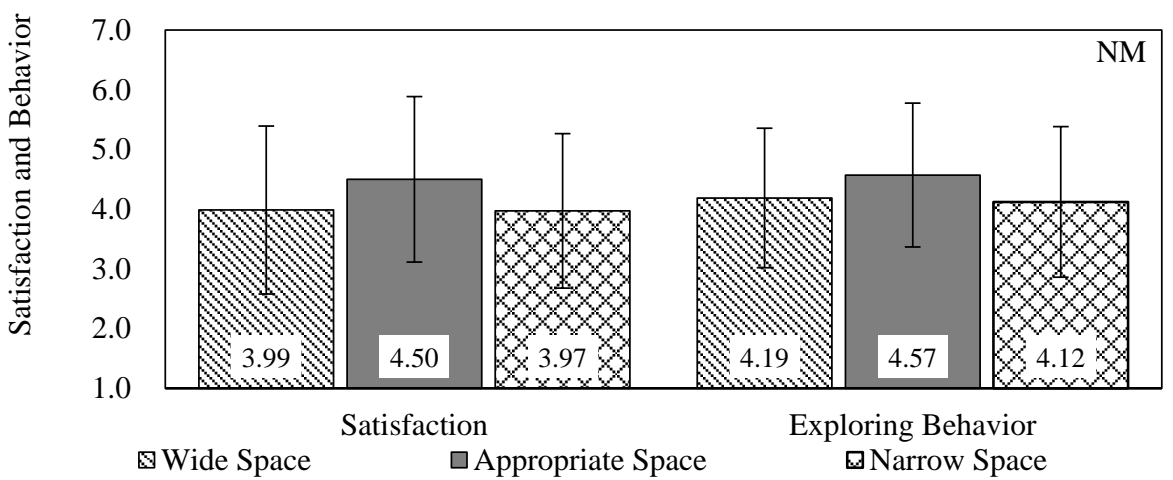

(a) Satisfaction and Exploring Behavior (NM)

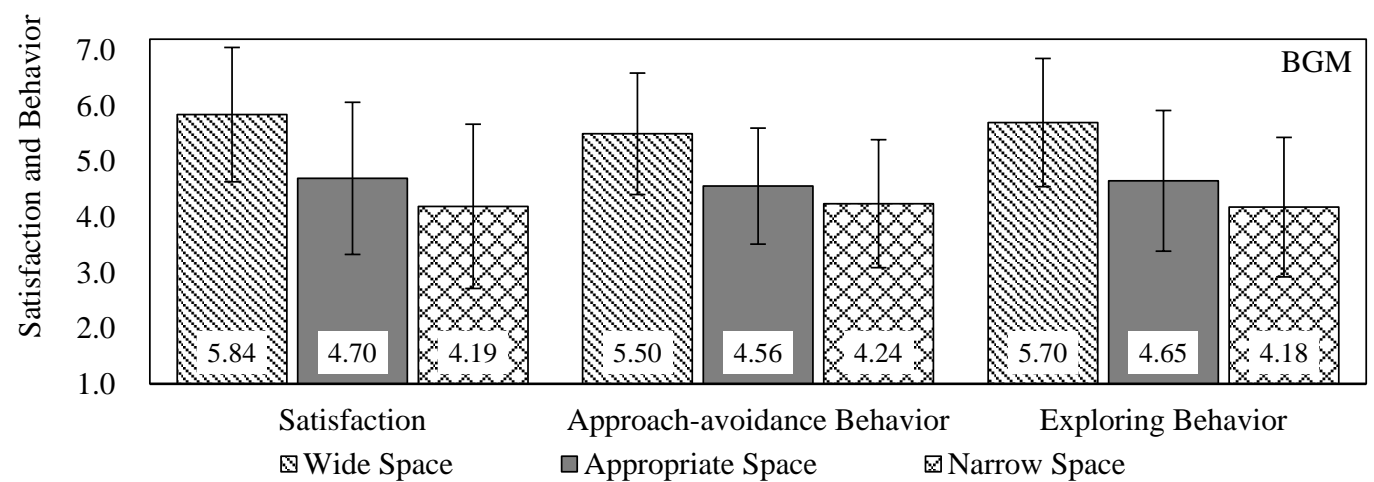

(b) Satisfaction and Behavior Intention (BGM)

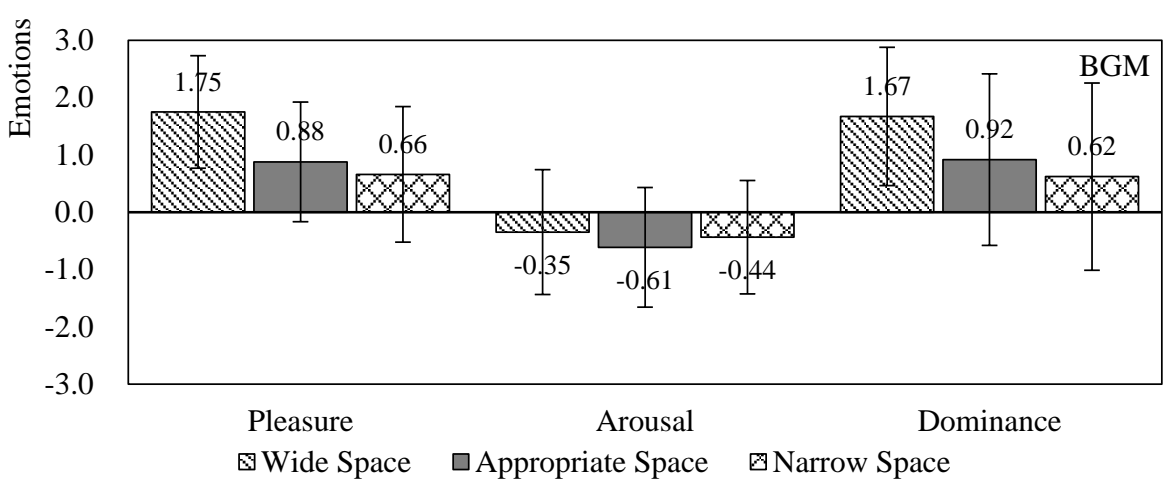

(c) Emotional Responses (BGM)

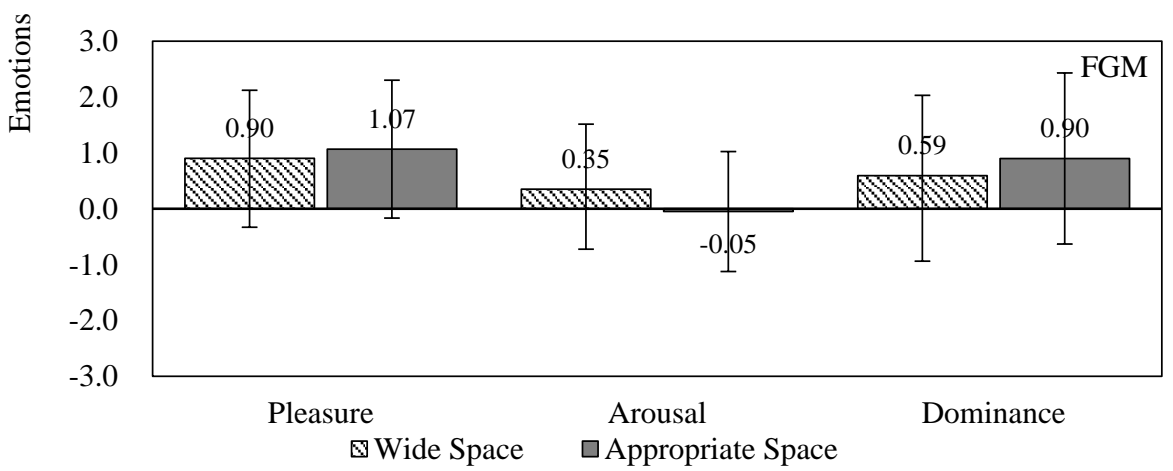

(d) Emotional Responses (FGM)

Fig. 6. Effects of Space Types on Individual Responses 
The influence of music settings on individual responses in a large atrium is shown in Fig. 7. The effect of music on levels of satisfaction, behavior intention, pleasure, and dominance in a large atrium is similar to the overall trends (Fig. 4).

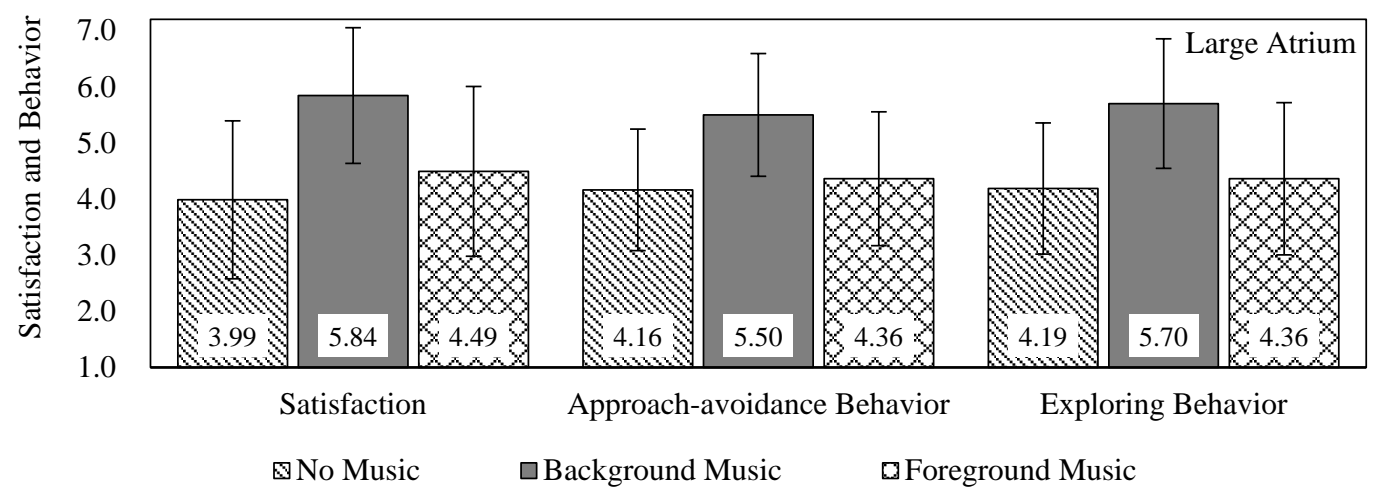

a) Satisfaction and Behavior Intention

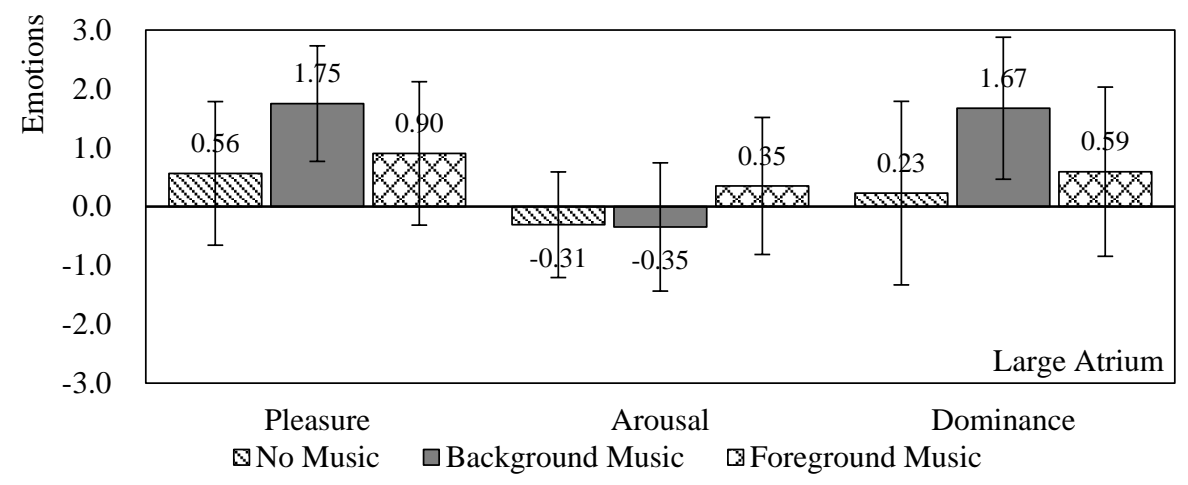

b) Emotional Responses

Fig. 7. Impact of Music Settings on Individual Responses in Large Atrium Space

However, compared with the overall trends, Fig. 8 shows the different effects of music in a large atrium space. With BGM, satisfaction, behavior intention, pleasure, and dominance are significantly enlarged, as shown in Fig. 8(a-d, f). The increased satisfaction value and behavior intention increase by $0.87-1.11$ with BGM compared with $\mathrm{NM}$ and FGM. As for pleasure and dominance of emotional responses, the value of BGM increases by $0.73-0.80$. However, the effect of FGM, which influences arousal significantly, shows no obvious difference in large atrium space from other types of space. The reason is explained as follows: compared with other space, the boundaries of the large atrium are blurred, and the size of the space in which the participant is situated is beyond his or her control. People in it will be more alert (average arousal is -0.15 in large atrium and -0.42 in other spaces) and deal with the environment stimuli more aggressively. Thus, the response results appear much stronger. 


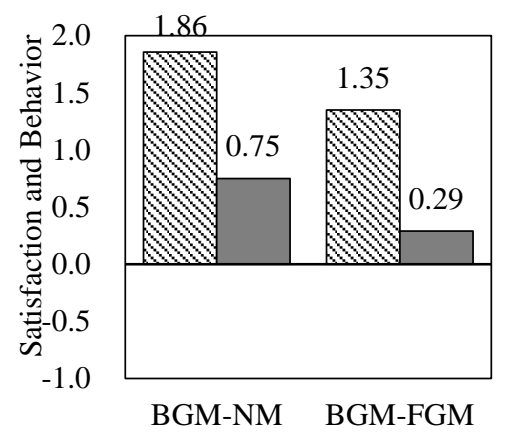

(a) Satisfaction

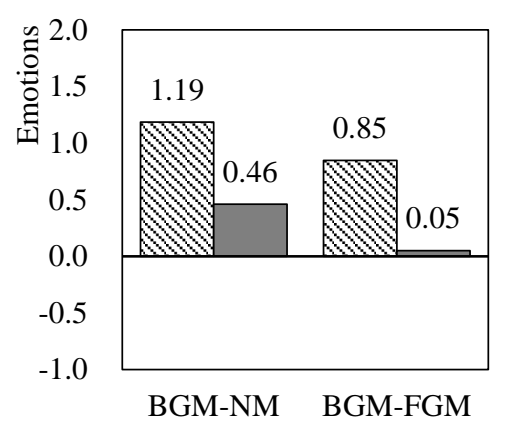

(d) Pleasure

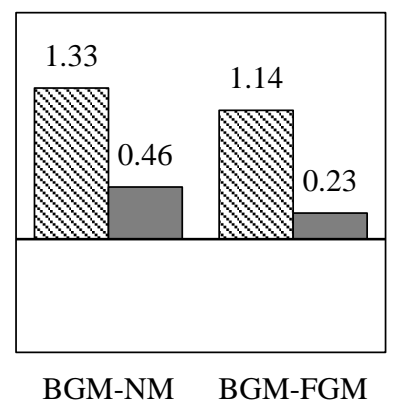

(b) Approach-Avoidance Behavior

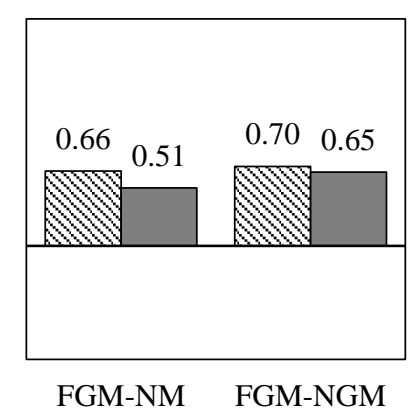

(e) Arousal

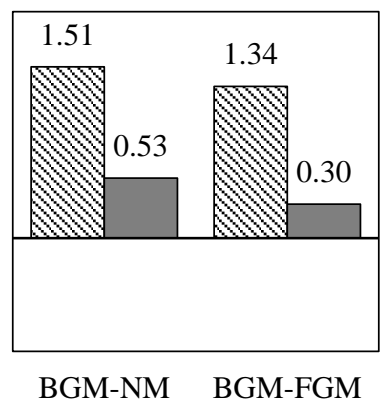

(c) Exploring Behavior

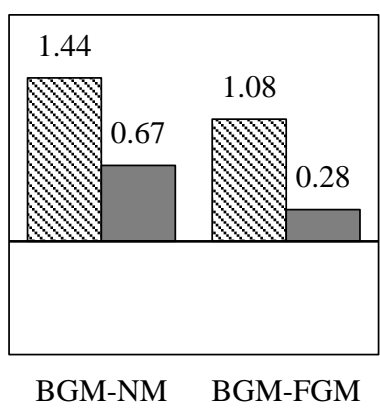

(f) Dominance

$\$$ Large Atrium Space $\square$ General

Fig. 8. Differences of Individual Responses between Large Atrium Space and Other Spaces

\subsection{Personal factors and individual responses}

\subsubsection{Gender differences}

Individual responses of different genders are found. With NM, men's satisfaction is 4.29, which is significantly higher than women's 3.88 . With FGM, men's arousal is 0.33 while women's is -0.10 . Subjects' arousal is significantly increased with FGM, but men are more affected by music than are women, with a score that is 0.43 higher. Results show that in the specific music setting, men are more tolerant and alert, while women are more dissatisfied and eased.

\subsubsection{Age differences}

As for age, individual responses by age are shown in Fig. 9. From Table 7, it was found that in the old group, each individual response is not significantly affected by music except satisfaction. Meanwhile, the individual responses of the young and mid-age groups are significantly influenced, but music's influence on the young group's emotional responses is more comprehensive. As with pleasure and dominance, BGM and FGM can significantly improve grades compared with $\mathrm{NM}$, and there is a significant difference regarding the three kinds of music's impact on arousal for the young group. These results further demonstrate that as people get older they are less sensitive to music, and the impact of music is smaller, which confirms previous research [53]. 


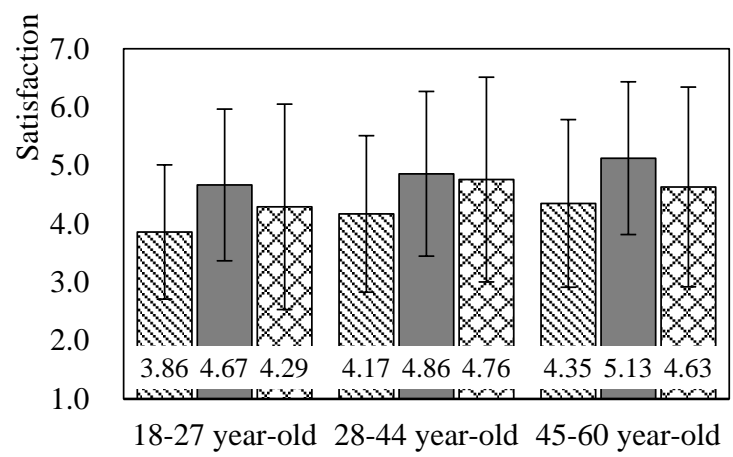

(a) Satisfaction

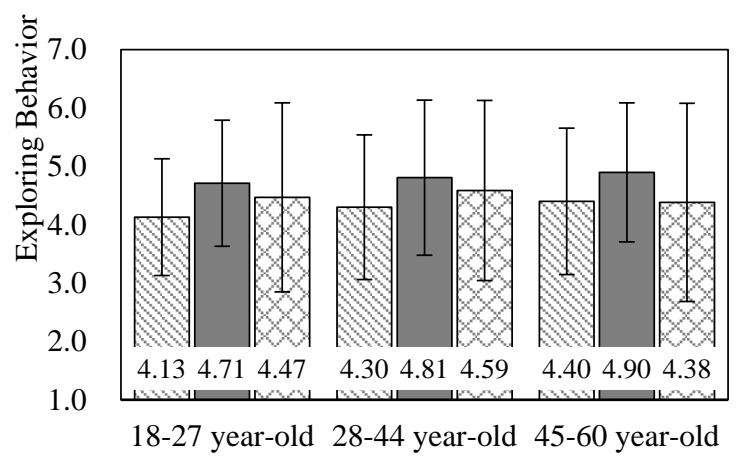

(c) Exploring Behavior

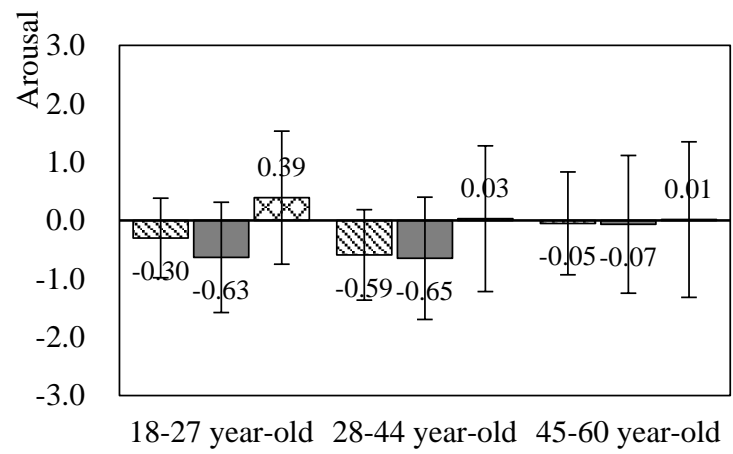

(e) Arousal

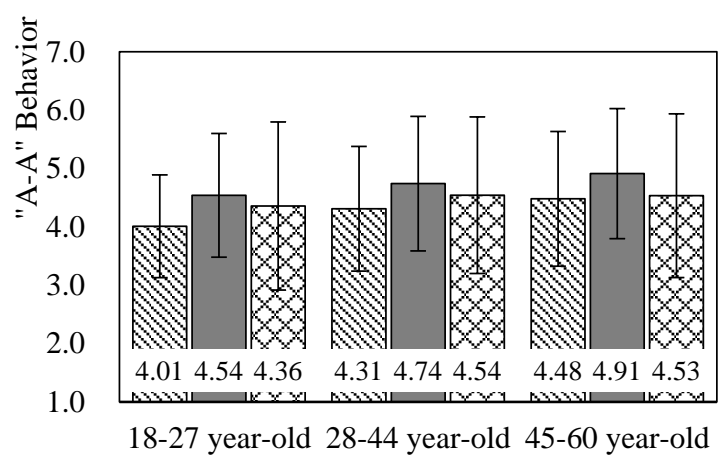

(b) Approach-avoidance Behavior

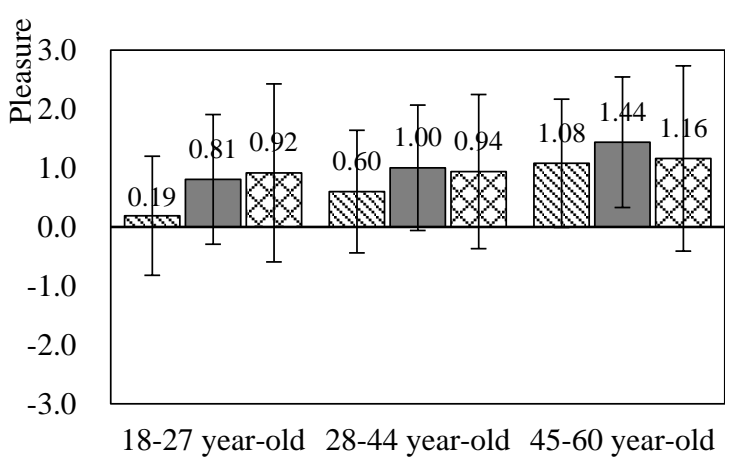

(d) Pleasure

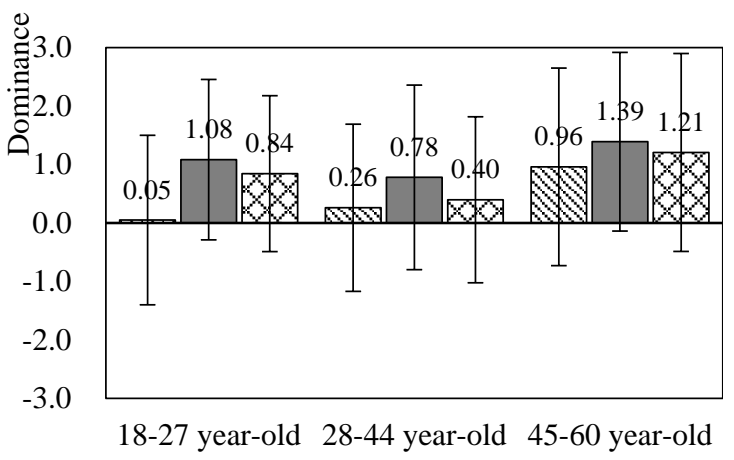

(f) Dominance

$\square$ No Music $\square$ Background Music $\quad$ Foreground Music

Fig. 9. Individual Responses of Different Ages

The age difference under each music setting was also analyzed, as shown in Fig. 10. First, under the condition of NM, emotional responses of different ages are quite different: young people's pleasure is significantly lower than that of the oldest group; the arousal of the mid-aged group is the lowest, while that of the oldest group is the highest. With $B G M$, the overall trend is similar to that with NM, but the age groups with significant differences are reduced. There is no significant age difference in individual responses with FGM. Results show that NM causes significant different emotional responses at all age levels, and with the emergence of music to the increase of music content, differences 
in emotional responses by age gradually reduce until they disappear. In addition, the comparison of mean values found that the oldest group has the highest score, indicating that they have more positive emotion responses to environmental stimuli and are more tolerant to the overall environment.

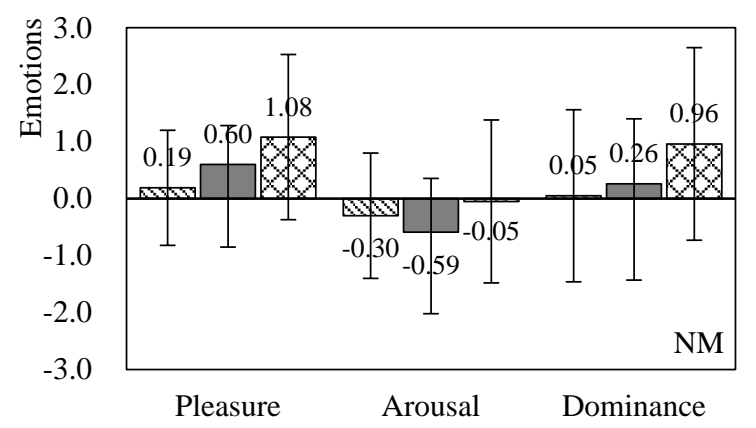

(a) Emotional Responses with NM

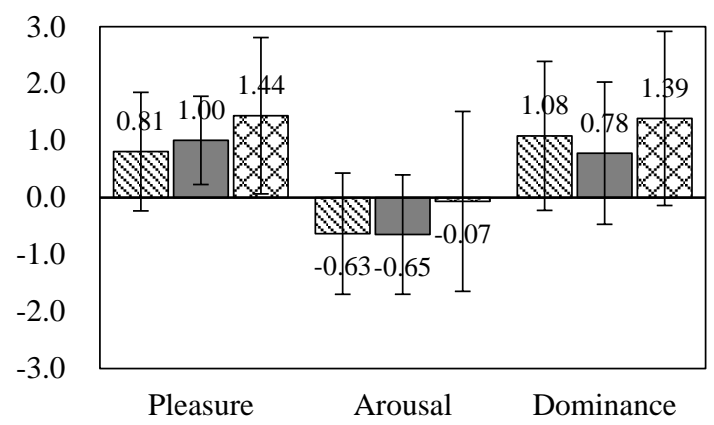

(b) Emotional Responses with BGM

$\square 18$ - 27 year-old $\square 28$ - 44 year-old $\quad$ 45 - 60 year-old

Fig. 10. Emotional Responses of Different Ages with NM and BGM

\section{Conclusions}

This study utilized an audio-visual test of environment perception in shopping malls to examine the effects of different musical settings on people's emotions and behavior. From the results, the following can be concluded:

First, background music can strengthen satisfaction significantly and promotes approach behavior, as well as increases the desire to browse and explore. Foreground music can significantly affect the arousal emotion.

Second, this study found that with no music, evaluations of appropriate space are higher, and when BGM exists, large spaces are evaluated more positively than smaller spaces except in the case of arousal, whereas foreground music has a statistically significant effect on arousal in large spaces compared with narrow ones. In terms of large atria in shopping malls, which are becoming increasingly common in the design of spaces, music is much more powerful than in other spaces.

Finally, as for personal factors, the results and application vary according to different kinds of people. With no music, men show higher satisfaction compared with women, and with foreground music, they show more arousal. Meanwhile, music types play a more important role on young shoppers than on older ones, and people in the oldest age group were shown to be more tolerant of sound in shopping environments.

The results indicate that it is necessary to improve the acoustics in public shopping environments. Designers and managers should design the acoustic environment according to the use of the specific space and the people they want to affect. For instance, a more peaceful atmosphere with background music is more conducive for spaces for people to meet and wait, while foreground music is more appropriate for spaces adjacent to shopping areas, display spaces, and other areas where an increase in people's participation level is desired. In addition, as young people are more sensitive to 
environmental changes in sound, areas targeting this group require more attention to the designed sound environment. The latest popular music and songs more appropriate for young people will have significant effects on their emotion and behavior. It is also important to consider the effects of space shapes. For example, sound propagation in long spaces could be rather different from regularly-shaped spaces $[67,68]$.

\section{Declarations of interest}

This work was supported by the National Natural Science Foundation of China [grant number 51778169]. 


\section{References}

[1] Akhter H, Reardon R, Andrews C. Influence on brand evaluation: consumers' behavior and marketing strategies. J Consum Market 1987;4(3):67-74.

[2] Aletta F, Kang J. Towards an urban vibrancy model: a soundscape approach. Int J Environ Res Public Health 2018;15(8):1712. https://doi.org/10.3390/ ijerph15081712.

[3] Aletta F, Lepore F, Kostara-Konstantinou E, Kang J, Astolfi A, et al. An experimental study on the influence of soundscapes on people's behavior in an open public space. Appl Sci 2016;6(10):276-87.

[4] Areni CS. Examining managers" theories of how atmospheric music affects perception, behaviour and financial performance. J Retail Consum Serv 2003;10(5):263-74.

[5] Bakker I, Boon JD. Zorg voor mens en omgeving. Het zintuig als maatstaf 2012.

[6] Bakker I, van der Voordt TVD, Vink P, de Boon J, et al. Pleasure, arousal, dominance: Mehrabian and Russell revisited. Curr Psychol 2014;33(3):405-21.

[7] Bellizzi JA, Hite RE. Environmental color, consumer feelings, and purchase likelihood. Psychol Market 1992;9(5):347-63.

[8] Bellizzi JA, Crowley AE, Hasty RW. The effects of color in store design. J Retail 1983;59(1):21-45.

[9] Berman B, Evans JR. Retail management: a strategic approach. Ed Upper Saddle River, NJ: Prentice Hall/nj; 1989.

[10] Bitner MJ. Evaluating service encounters: the effects of physical surroundings and employee responses. J Market 1990;54(2):69-82.

[11] Bitner MJ. Servicescapes: the impact of physical surroundings on customers and employees. J Market 1992;56(2):57-71.

[12] Brown AL, Kang J, Gjestland T. Towards standardization in soundscape preference assessment. Appl Acoust 2011;72(6):387-92.

[13] Chebat J, Gelinaschebat C, Filiatrault P. Interactive effects of musical and visual cues on time perception: an application to waiting lines in banks. Percept Mot Skills 1993;77(1):995-1020.

[14] Chen B, Kang J. Acoustic comfort in shopping mall atrium spaces: a case study in Sheffield Meadowhall. Archit Sci Rev 2004;47(2):107-14.

[15] Denora T, Belcher S. "When you"re trying something on you picture yourself in a place where they are playing this kind of music" - musically sponsored agency in the British clothing retail sector. Sociol Rev 2010;48(1):80-101.

[16] Donovan R, Rossiter JR. Store atmosphere: an environment psychology approach. J Retail 1982;58:3457.

[17] Dubé L, Morin S. Background music pleasure and store evaluation: intensity effects and psychological mechanisms. J Bus Res 2001;54(2):107-13.

[18] Dubé L, Chebat J, Morin S. The effects of background music on consumers' desire to affiliate in buyer seller interactions. Psychol Market 1995;12 (7):305-19.

[19] Fanng C. Satisfying shoppers psychological needs: from public market to cyber-mall. J Environ Psychol 2003;23(4):439-55.

[20] Floyd MF. Getting beyond marginality and ethnicity: the challenge for race and ethnic studies in leisure research. J Leisure Res 1998;30(1):3-22. 
[21] Garlin FV, Owen K. Setting the tone with the tune: a meta-analytic review of the effects of background music in retail settings. J Bus Res 2006;59 (6):755-64.

[22] Grewal D, Baker J, Levy M, Voss GB, et al. The effects of wait expectations and store atmosphere evaluations on patronage intentions in service-intensive retail stores. J Retail 2003;79(4):259-68.

[23] Holbrook MB, Batra R. Assessing the role of emotions as mediators of consumer responses to advertising. J Consum Res 1987;14(3):404-20.

[24] Husain G, Thompson WF, Schellenberg EG. Effects of musical tempo and mode on arousal, mood, and spatial abilities. Music Percept 2002;20(2):151-71.

[25] ISO. Acoustics - soundscape - part 1: definition and conceptual framework. In I.T.S. Noise (Ed.) ISO 12913-1:2014; 2014.

[26] Kämpfe J, Sedlmeier P, Renkewitz F. The impact of background music on adult listeners: a metaanalysis. Psychol Music 2010;39(4):424-48. https://doi.org/10.1177/0305735610376261.

[27] Kang J. Urban sound environment. London: Taylor \& Francis Incorporating Spon; 2007.

[28] Kang J, Schulte-Fortkamp B, editors. Soundscape and the built environment. London: Taylor \& Francis Incorporating Spon; 2016.

[29] Kang J. From dBA to soundscape indices: managing our sound environment. Front Eng Manage 2017;4(2):184-92.

[30] Kellaris JJ, Mantel SP, Altsech MB. Decibels, disposition, and duration: the impact of musical loudness and internal states on time perceptions. In: Corfman KP, Lynch JG, editors. NA - Advances in Consumer Research. Provo, UT: Association for Consumer Research. Advances in Consumer Research; 1996. p. 498503.

[31] Kim D, Areni CS. The Influence of background music on shopping behavior: classical versus top-forty music in a wine store. Adv Consum Res 1993;20:336-40.

[32] Kotler P. Atmospherics as a marketing tool. J Retail 1973;49(4):48-64.

[33] Kuribayashi R, Nittono $H$. Speeding up the tempo of background sounds accelerates the pace of behavior. Psychol Music 2015;43(6):808-17. https://doi.org/10.1177/0305735614543216.

[34] Lam SY. The effects of store environment on shopping behaviors: a critical review. Adv Consum Res Assoc Consum Res 2001;28(1):190-7.

[35] Lavia LR, Witchel HJ, Kang J, Aletta F, et al. In: A preliminary soundscape management model for added sound in public spaces to discourage anti-social and support pro-social effects on public behaviour. Aachen: DAGA 2016; 2016. https://doi.org/10.13140/RG.2.1.1392.4242 2016.

[36] Lee D, Henderson A, Shum D. The effect of music on preprocedure anxiety in Hong Kong Chinese day patients. J Clin Nurs 2004;13(3):297-303.

[37] Leng CY, Botelho D. How does national culture impact on consumers' decisionmaking styles? A cross cultural study in Brazil, the United States and Japan. U. S. Gov Print Office 2010;2010:89-92.

[38] Lewin K, Heider F, Heider G. Principles of topological psychology. New York, London: McGraw-Hill; 1936. p. $94-5$.

[39] Mattila AS, Wirtz J. Congruency of scent and music as a driver of in-store evaluations and behavior. J Retail $2001 ; 77(2): 273-89$.

[40] Mehrabian A, Russell JA. An approach to environmental psychology. Cambridge, MA: The MIT Press; 1974. 
[41] Meihua Z, Chung KD. Comparative analysis of family structure and function between China and USA. J East China Univ Sci Technol (Soc Sci Ed) 2008;2008 (4):26-30.

[42] Meng Q, Kang J. Influence of social and behavioural characteristics of users on their evaluation of subjective loudness and acoustic comfort in shopping malls. PLoS One 2013;8(1):. https://doi.org/10.1371/journal. pone.0054497e54497.

[43] Milliman RE. Using background music to affect the behavior of supermarket shoppers. J Market $1982 ; 46(3): 86-91$.

[44] North AC, Hargreaves DJ, Mckendrick J. The influence of in-store music on wine selections. J Appl Psychol 1999;84(2):271-6.

[45] Oakes S. The influence of the musicscape within service environments. J Serv Mark 2000;14(7):53956.

[46] Oakes S. Musical tempo and waiting perceptions. Psychol Market 2003;20 (8):685-705.

[47] Osgood CE, Suci GJ, Tannenbaum PH. The measurement of meaning. Urbana: University of Illinois Press; 1957. p. 342.

[48] Pan Y, Meng Z. Influence of attention in visual-auditory on visual masking effect. Video Eng 2011.

[49] Payne LL, Mowen AJ, Orsega-Smith E. An examination of park preferences and behaviors among urban residents: the role of residential location, race, and age. Leisure Sci 2002;24(2):181-98.

[50] Pheasant RJ, Fisher MN, Watts GR, Whitaker DJ, Horoshenkov KV, et al. The importance of auditoryvisual interaction in the construction of "tranquil space". J Environ Psychol 2010;30(4):501-9.

[51] Pheasant R, Horoshenkov K, Watts G, Barrett B, et al. The acoustic and visual factors influencing the construction of tranquil space in urban and rural environments tranquil spaces-quiet places? J Acoust Soc Am 2008;123 (3):1446-57.

[52] Rosenberg MJ. Attitude organization and change: an analysis of consistency among attitude components. New Haven: Yale University Press; 1960. p. 1960.

[53] Russell JA, Lanius UF. Adaptation level and affective appraisal of environment. J Environ Psychol 1984;4(2):119-35.

[54] Sakharov DS, Davydov VI, Pavlygina RA. Intercentral relations of the human EEG during listening to music. Fiziol Cheloveka 2005;31(4):392-7.

[55] Song F, Kang J, Jin H. Evaluation and comparison of sound environment in above- and underground shopping malls. Appl Acoust 2011;30(5):377-86.

[56] Sweeney JC, Wyber F. The role of cognitions and emotions in the music approach-avoidance behavior relationship. J Serv Mark 2002;16(1):5169.

[57] Tai SHC, Fung AMC. Application of an environmental psychology model to instore buying behaviour. Int Rev Retail Distrib Consum Res 1997;7(4):311-37.

[58] Tansik DA, Routhieaux R. Customer stress-relaxation: the impact of music in a hospital waiting room. Int J Serv Ind Manage 1990;10(1):68-81.

[59] Turley LW, Milliman RE. Atmospheric effects on shopping behavior: a review of the experimental evidence. J Bus Res 2000;49(2):193-211.

[60] Watts GR, Pheasant RJ. Tranquility in the Scottish Highlands and Dartmoor National Park - the importance of soundscapes and emotional factors. Appl Acoust 2015;89:297-305.

[61] Yalch R, Spangenberg E. Effects of store music on shopping behavior. J Consum Market 1990;7(2):55- 
63.

[62] Yalch R, Spangenberg E. An environmental psychological study of foreground and background music as retail atmospheric factors. Chicago 1988:106-10.

[63] Yalch R, Spangenberg E. The Effects of music in a retail setting on real and perceived shopping times. J Bus Res 2000;49(2):139-47. https://doi.org/10.1016/S0148-2963(99)00003-X.

[64] Yorukoglu PND, Kang J. Analysing sound environment and architectural characteristics of libraries through indoor soundscape framework. Arch Acoust 2016;41:203-12.

[65] Yorukoglu PND, Kang J. Development and testing of indoor soundscape questionnaire for evaluating contextual experience in public spaces. Build Acoust 2017;24(4):307-24.

[66] Zhao W. Optimization design of acoustic and daylight environment for commercial building atria. Harbin Institute of Technology; 2016.

[67] Kang J. A method for predicting acoustic indices in long enclosures. Appl Acoust 1997;51(2):169-80.

[68] Kang J. The unsuitability of the classic room acoustical theory in long enclosures. Archit Sci Rev 1996;39(2):89-94.

[69] Gorn GJ, Goldberg ME, Basu K. Mood, awareness, and product evaluation. JConsumer Psychol 1993;2(3):237-56. 